\section{Dr Cecil Todes}

\section{Formerly Consultant Child Psychiatrist, Paddington Centre for Psychotherapy}

Cecil Todes was born on 29 May 1931 in Johannesburgh, South Africa. Todes was a consultant child psychiatrist, psychoanalyst and author of an original, and now classic book, about his own Parkinson's disease, Shadow Over My Brain.

On its first publication, in 1990, the book was highly praised in its preface by the eminent neurologist and writer, Oliver Sacks. As well as being of great interest to the general reader, and to the individual with Parkinson's disease, it should be essential reading for all medical students interested in neurology as well as for all trainee specialist neurologists. Its uniqueness is that it is the first book about Parkinson's disease ever written and researched by a patient with Parkinson's.

Todes came to the UK from a Jewish South African background in the mid1950s to escape the oppressive apartheid regime prevailing at the time. By that time, he had already qualified in dentistry at the University of the Witwatersrand. He gained further qualifications in London in the special interest of orthodontics and also gained a fellowship in dentistry. Then, he decided to become a physician, and afterwards, in order, a psychiatrist and an analyst.

In pursuit of this ambition, in 1957 he enrolled as a medical student at the West London Hospital. After two pre-General Medical Council registration jobs, Todes had the brainwave of going to the USA to take up a Harvard psychiatric training residency in Boston. It was while in America that he married Lili Loebl, a journalist for Newsweek.

On his return to the UK he gained the DPM in 1965 and soon was appointed Senior Registrar in Adolescent Psychiatry at the Tavistock Clinic where he was privileged to be trained by Dr John Bowlby, the

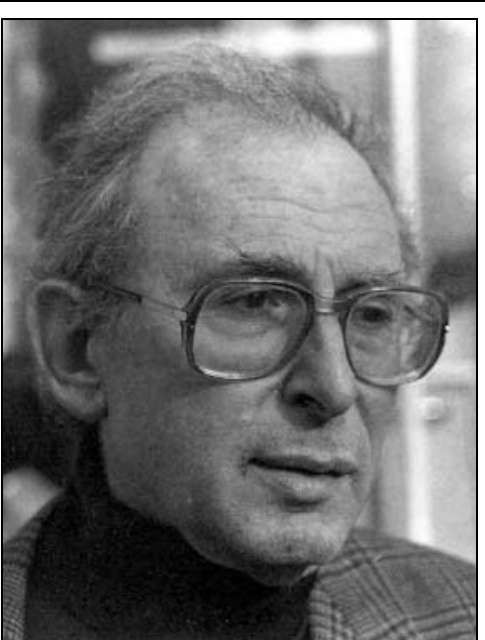

distinguished psychoanalyst and pioneer in attachment theory. Attachment theory and loss were to influence profoundly Todes's subsequent ideas and development.

Further training was given by the eclectic paediatrician and psychoanalyst Dr Donald Winnicott, while, at the same time, undergoing Freudian training psychoanalysis with Dr Lothair Rubinstein. In 1970 he was appointed Consultant Child Psychiatrist at Barnet Hospital, transferring shortly afterwards to Great Ormond Street Hospital and later to the Paddington Centre for Psychotherapy, where he remained until 1987 when he took early retirement from the National Health Service because of Parkinson's disease. Nevertheless, he continued practicing private psychoanalysis and psychotherapy until 1992

In 1971 his Parkinson's was so mild that the then professor of neurology at the London Hospital told him to ignore his symptoms, the first of which, interestingly, was when his automatic watch stopped when he ceased to swing his left arm while walking.

In 1977, Todes publicly broke his association with Anna Freud and her clinic for disturbed young children, after he had decided that her insistence that assessments and treatment methods must be only by herself and her students rather than by trained child therapists, were outmoded by modern standards. He thus demonstrated that he was not to be overawed by the big names of psychoanalysis and others who were regarded as members of Freud family cult.

Perhaps the most important thrust of Shadow Over My Brain is the possible psychosomatic causation of Parkinson's disease, that of the early loss of a loved one, in genetically predisposed individuals. Todes's mother had died just before his seventh birthday and he experienced this as a great loss. His own training psychoanalysis probably revived this early traumatic memory and its strong emotions, and this was reinforced when his own training psychoanalyst suddenly died in his presence in Vienna.

Shadow Over My Brain reveals a resourcefulness, determination and rare originality, and for him, as the victim of the parkinsonian condition, was an opportunity to explore the relationship between mind and body in both the sick and the healthy. It also portrays his enormous courage in trying out a range of new medications and treatments for the disease (Todes even underwent a radical and unsuccessful foetal cell transplant into his brain.) Although he was befriended and treated by leading neurologists, he also felt they lost interest in his case when it, obviously, became very chronic. He describes how he experienced episodes of breaks with reality as a side-effect of medication, leading to hospitalisation.

Cecil Todes died on 5 June 2008. He leaves behind his wife, Lili Loebl, their daughter and two sons.

Nathaniel Minton

\section{doi: 10.1192/pb.bp.108.023846}

First published by The Independent, 15 July 2008. Reproduced with kind permission. 